\title{
The Use of Play Therapy Mediums in a Stress Management Program with Corporate Employees
}

\author{
Deidré Nel \\ G. M. Spies
}

Deidré Nel, PhD, has been training corporate employees for the past six years. G. M. Spies, PhD, was the dissertation supervisor for Deidré Nel. She is Senior Lecturer in Department of Social Work and Criminology, University of Pretoria, South Africa 0001. Address correspondence to: Deidré Nel, PhD, PO Box 25071 Monument Park, South Africa 0105 (E-mail: dnel@yebo.co.za).

The article presented here is a result of Deidré Nel's doctoral dissertation, which she completed in October 2005.

ABSTRACT. There is a growing need for corporate employees to manage their stress levels. Stress is experienced because of an excessive workload, a high work pace, difficult work schedules, role conflict, and uncertainty regarding career security, poor interpersonal relationships and unpleasant working conditions. It manifests in symptoms such as conflict, depression, absenteeism, headaches and hypertension. Research was conducted to determine if the use of play therapy mediums in a stress management program for corporate employees has a positive effect on their stress levels. The research findings indicated that stress levels improved after a stress management program incorporating play therapy was presented to the corporate employees.

KEYWORDS. Play therapy mediums, corporate employees, organisation stress, stress management program

Deidré Nel, PhD, has been training corporate employees for the past six years. G. M. Spies, PhD, was the dissertation supervisor for Deidré Nel. She is Senior Lecturer in Department of Social Work and Criminology, University of Pretoria, South Africa 0001.

Address correspondence to: Deidré Nel, PhD, PO Box 25071 Monument Park, South Africa 0105 (E-mail: dnel@yebo.co.za).

The article presented here is a result of Deidré Nel's doctoral dissertation, which she completed in October 2005. 


\section{INTRODUCTION}

People play from their earliest months of life and continue to do so in some form or other until they go to the big playground in the sky.

-Jennings, 1993

Stress is a word that has been used more and more in the last few years. During the seventeenth century stress referred to hardship, adversity and affliction (Keefe, 1988). In today's world it refers to the inevitable challenges that people have to face every day; some challenges are enjoyed and some challenges are full of strife, but they have to be faced. These challenges have a certain effect on people and often this effect is of stress.

Research was conducted by the authors to ascertain whether a Stress Management program, which included play therapy mediums, would have a positive effect on the stress levels of corporate employees. This article will show the findings of the research. But before the research findings are discussed, attention will be given to key concepts for better understanding of the study and the research problem.

\section{DEFINING STRESS}

The difficulty in defining stress lies in the fact that the word is often used to describe both the sources and the effects of the stressful situation. According to Auerbach and Gramling (1998), the word "stress" comes form the Latin word "strictus" and the term is used to explain both a stimulus and a response to that stimulus. Williams (1994) describes stress as "what happens to us when things go wrong. It is something we suffer from and has a negative quality. It has a physical, a psychological and an emotional component. There does not need to be an external cause, and the consequences of being under stress can affect our physical, mental and social health."

\section{Stress Management Programs}

There are many different opinions regarding what a stress management programs should include. According to Kantor et al. (1997), interventions can include skills that reduce or modify exposure to stress, skills that reduce excessive physiological functioning and techniques that will facilitate expression of the stress response in a healthy manner. 
Such a program will address the person's lifestyle by focusing on nutrition, exercise, relationships, work environment, coping mechanisms

and health beliefs and behaviours (Kantor et al., 1997).

The focus of this stress management program was to create awareness of stress and the causes of stress in the lives of corporate employees. The corporate employees had the opportunity to de-stress during the program and acquired skills to help them relax effectively.

\section{PLAY THERAPY MEDIUMS}

Play therapy mediums such as sand, clay and drawings were incorporated into a stress management program for corporate employees. These play therapy mediums are effective in creating an environment in which people can become more aware of themselves and make sensory contact with themselves (Schoeman, 1996). Play is not an activity with which adults are usually associated, but play therapy mediums were incorporated into the stress management program to give corporate employees the opportunity to become more aware of the causes of stress in their lives. Ward-Wimmer (2003) states that "for adults, play continues as an important vehicle because it fosters numerous adaptive behaviours including creativity, role rehearsal and mind/body integration."

\section{Defining Play}

Landreth in Schaefer (1993) states that play is often easier to recognise and observe than it is to define. According to West (1996) play allows opportunities for physical, emotional, cognitive and social growth and is often pleasurable, spontaneous and creative. Play can reduce frightening and traumatic events; it may relieve anxiety and tension; it can aid relaxation, amusement and enjoyment.

Apart from this, play can be used as a tool in therapy and allows for a cathartic release of feelings and emotions (West, 1996). The cathartic release is one of the reasons that play therapy is effective as part of a stress management program. The corporate environment does not allow much space for the ventilation of feelings, and this program gave the participants the opportunity to relax and make contact with issues in their lives and in their working environment.

\section{Different Play Therapy Mediums}

There are different types of play therapy mediums that can be used in therapy or in a training program. Some participants enjoy certain activities more that others. This is an individualised reaction to the play therapy mediums and the social worker should be aware of this and allow space for it.

\section{Sand}

The sand tray technique was initially created by Margaret Lowenfeld. 
She called it the "Miniature World Technique." With this technique she attempted to structure play. Children were instructed to build a series of scenes in the sand tray with an assortment of objects. Lowenfeld interpreted the different "world scenes" in terms of criteria regarding the content, themes, changes, process and space.

"It [the sand tray] is an apparatus . . . which will give a child power to express his ideas and feelings; it is independent of knowledge and skill; it is capable of representation of thought simultaneously in several places at once; it allows representation of movement and yet [is] sufficiently circumscribed to make a complete, whole . . . [it] combines elements of touch and sensation, as well as sight, and [it is] entirely free from a necessary relation to reality." (Lowenfeld, as quoted in Gitlin-Weiner, Sandgrund \& Scheafer, 2000)

Sand is a tactile medium that helps participants to make use of their senses to create greater self-awareness. Most people enjoy the feeling of sand between their fingers. Sand play adds a tactile dimension to play and this increases the participant's sensory awareness (Carey, 1990). The researcher has experienced that children as well as adults enjoy working with the sand. Oaklander (1988) mentions that people spontaneously start playing in the sand tray without motivation. The sand tray gives the person a sense of control because it is so much smaller that the real world. Sand play allows the person to be in total control of the activity and to experience a sense of his/her own inner power. Sand play encourages verbalisation in those cases where poor verbal skills exist (Oaklander, 1988). Fears and fantasies that are usually suppressed can be projected into the sand (West, 1992). Last but not the least, sand therapy provides an opportunity to ventilate feelings (McMahon, 1992).

There is often an inconsistency between feelings and thoughts. The sand tray helps participants who have difficulty in expressing themselves to ventilate more freely. They metaphorically play out the traumatic event that was experienced and because the situation is reconstructed on a smaller scale, the participants feel empowered. After verbalisation of emotions participants start to work on a solution to the situation and can play that out in the sand tray. Carey (1990) mentions that the participants are in control of the sand tray and therefore they experience a sense of their own power.

Clay

Clay is a medium that people of all ages and from all backgrounds can relate to. People who grew up in rural areas often had to make their toys from clay or mud as children because there were no other toys available, so they usually enjoy working with the clay. City children seldom play with clay in an informal setting, and therefore they enjoy the clay work because it is often a new experience to them. It can be used to develop or express touch sensation, but also to activate other senses and to provide the context for imaginative play. 
Oaklander (1988) refers to clay as one of her favourite mediums. She mentions the following as advantages of the use of clay: (1) It leaves a person feeling good and relaxed. (2) It is flexible and malleable. (3) It affords opportunity for flow between itself and the user unequalled by any other material. (4) It is easy to become one with the clay. (5) It offers both tactile and kinaesthetic experience (opportunity for sensory experience). And (6) It brings people closer to their feelings. The sensuousness of the clay often gives them a bridge between their senses and their feelings. Anger can be ventilated through clay in numerous ways. Those who are insecure and fearful can feel a sense of control and mastery through clay and it is appealing to every age.

Winship and Haigh (1998) suggest another advantage of clay is that it can be used effectively as a group activity. The group can work together to create a sculpture and a discussion can follow from there. Furthermore, West (1996) mentions that clay allows for messy and sophisticated symbolic play, depending on what the participants want to do with it. It allows for three-dimensional work. It is flexible and can be moulded and changed. It sometimes has more reality than a painting or drawing and people can change their minds as they go along and thus change their creation.

During the stress management program the employees had the opportunity to create their stressors in the clay, take control and ventilate anger by hitting the clay, throwing it or breaking it. The use of the clay as play therapy medium facilitated this process (Schoeman \& Van der Merwe, 1996). Therefore, it was empowering for the participants as they felt in control of the stressful situation, which in real life seems beyond their control.

\section{Drawing}

Drawing is one of the mediums used most often by play therapists. Oaklander (1988) suggests that "drawings are like dreams, they tend to make accurate statements about what is going on in one's life at the moment." Piaget and Inhelder (in West, 1996) suggest further that "drawings and play have a special place in linking the internal and external domains."

Participants may realise that drawings are an extension of themselves. This is a popular medium with participants of all ages. According to West (1992) "art is a wonderful and satisfying form of self-expression." Thompson and Rudolph (1992) agree that drawings are often used to verbalise emotions. When emotions are verbalised the participants can start to regain balance in their lives.

There are many different types of drawings that can be used in play therapy.

Participants can be invited to create drawings according to certain themes (Oaklander, 1988). The following are examples of themes that they can be asked to draw: What you do when you are angry, a scary place, a place that makes you happy where you wish you could be, an ideal place, good or bad feelings, and the best and/or worst part of yourself 
and different images of yourself.

Some attention needs to be given to the interpretation of drawings.

West (1992) emphasises that interpretation and analysis by the therapist/

presenter is not necessary and she goes further and mentions that it can be very irresponsible to make interpretations of drawings of participants that partake in the activity. Occasionally, it may be appropriate to ask the creator of the drawing what is happening in the drawing and why, or invite them to tell the picture's story. The researcher asked the participating employees about their drawings. The participants were entitled to answer the questions to the extent that they felt comfortable. The importance here is that the therapist/presenter does not make an interpretation of the drawing without giving the employees who created the drawings, the opportunity to explain what the drawing is about. Most of the mediums in play therapy can be used as metaphors. According to Frey (in Schaefer, 1993), a participant can be asked to "draw his pain as it is right now, how the pain would look when it is 'all better,' and what will help the first picture to change into the second picture."

\section{Relaxation Play}

Relaxation is an important part of stress management. The stress management program that was presented to the employees included relaxation activities during each session. This enabled the employees to practice the relaxation activities and thus to ensure ongoing use after the stress management program was completed.

There are different types of relaxation play. It is however important to remember that individuals react differently to different relaxation activities. Some activities have a positive effect on some participants while others may create more stress and anxiety. Play is experienced by many people as a form of recuperating from the effects of the work that they do, and also part of the process for restoring the body after hard work. Lazarus is of the opinion that ongoing responding may have a negative influence on the person, and the negative effect is best eliminated by play (Ellis, 1973). The employee can find release in play and learn to cope better with reality. Relaxation play typically falls into three categories: relaxation with music, muscle relaxation and breathing exercises.

The use of music in therapy is becoming common practice to many therapists. It is a soothing medium and the use thereof in play therapy can be as enjoyable for the therapist as for the participants. Music can create a relaxed atmosphere for therapy and it can be used as an ice breaker too, which can prompt discussions, according to Van der Merwe (Schoeman\&Van der Merwe, 1996). It is important to take note of the fact that no person is too sick or too disabled to react to music. It has an effect on all people to a lesser or greater extent. The use of music in therapy is not focused on the verbal ability of the client-it is nonverbal and words are not necessary. This aspect of music was used positively during the stress management training. The music formed part of the experience and there was no added pressure on the individual to 
express him/herself.

With muscle relaxation the participants learn how to relax different muscle groups in their bodies, until they systematically relax their whole body. The participant's awareness of tension in his/her body is heightened. Their attention is focused on one group of muscles at a time.

They have to contract those muscles and keep them tense for approximately five to ten seconds, and then relax totally. The muscle groups are contracted one by one to ensure that the whole body relaxes (Van der Merwe in Schoeman \& Van der Merwe, 1996).

Muscle relaxation is often followed by guided imagery. The advantages of guided imagery are that participants gain a sense of mastery over their bodies and their feelings, and they are allowed to use their imagination to create hypothetical life situations and try out alternative solutions (O'Connor, 1997). During this activity the participants can be encouraged to lie down or sit as comfortably as possible and then the muscle relaxation is completed systematically.

Finally, breathing patterns often reveal our emotions. People who are anxious breathe faster and talk as they breathe in, but people who are depressed sigh regularly and talk as they breathe out (Looker \& Gregson, 2003). According to Schoeman (in Schoeman \& Van der Merwe, 1996) an important part of relaxation is breath flow. Aperson can be helped to do breathing exercises which provides more oxygen and enables better control over his body (Schoeman in Schoeman\&Van der Merwe, 1996).

\section{Dramatised Play}

Dramatised play allows the participants the opportunity to give life to their feelings, wishes and ideas through fantasy, imagery and metaphors.

According to Van Dyk (1994) (as quoted by Schoeman \& Van der Merwe, 1996) the advantages of dramatised play are that the participants can ventilate intense emotions and relive situations that are troubling, the participants are in control of the situation-and this is very empowering, communication is simplified, behavioural change can take place as the participants identify solutions for their situations. The word fantasy is derived from the Latin word "phantasticus." It incorporates different kinds of mental images such as fairy tales, fables, metaphors, symbolic and creative play and extensions of the person's imagination. Fantasy creates a world away from reality (Schoeman in Schoeman \& Van der Merwe, 1996). According to Marvasti (1997), "Tales and storytelling for the purpose of learning and healing is an ancient phenomenon. Fantasy and imagery are linked to each other." An important function of the fantasy is to allow the person to become aware of feelings, attitudes and opinions of others. This creates an atmosphere of understanding. The participants can consider alternative solutions to the problems at hand (Schoeman in Schoeman \& Van der Merwe, 1996). It is a way for the participants to realise that they are not the only people who experiencing that situation and that there are alternative solutions to the problem. A metaphor has the effect of allowing the reader to think of an ordinary 
object in a different way. It broadens the reader's outlook (Haarhoff, 1998) and it communicates with the person through images. These images often simplify understanding. Metaphors can build the bridge to make situations that are full of fear and emotion, more concrete (Schoeman in Schoeman \&Van der Merwe, 1996).

Metaphors are used every day in many different ways and people do not even realise that they are making use of metaphors. These metaphors describe the experiences that people have, and they create images in their minds while they are listening to someone or explaining an aspect to someone. Metaphors are useful in play therapy as people often forget a lot of the information given to them, but they remember the picture that was created by the metaphor.

\section{ORGANISATIONAL ENVIRONMENT}

There are many different aspects within the work situation that can cause stress among the employees. This is the environment in which the corporate employee finds him/herself and this is where he/she experiences stress. Some of these stressors are role interaction, over and under stimulation, decision making, organisational processes and individual attributes (Fincham \& Rhodes, 1999). Stress may lead to less productive individuals, more absenteeism, and stress related illnesses. Corporate employees form an essential part of the success of an organisation, and if stress is inhibiting their functioning, it could have a detrimental effect on the organisation.

Every person reacts to stress in a unique way. In South Africa the stress that corporate employees experience is also exacerbated by the transformation process that the country is still experiencing. Affirmative action and retrenchments occur frequently and very few people are assured of job safety. According to Grobler and Hiemstra (1998) about half of the working population in South Africa are unhappy in their jobs. Approximately $75 \%$ of the people, who consult with a psychiatrist, are experiencing problems that originate from a lack of job satisfaction and an inability to relax. In a survey that was done by employee assistance professionals in South Africa it was found that the most prevalent problems in the work place are family issues (25\%), stress (23\%), depression (21\%), alcoholism (14\%), job conflict (9\%) and drug abuse (2\%) (Van den Bergh, 2000). There are numerous stressors that employees have to contend with in the organisational environment such as change within the organisation, expectation of growth, globalisation, diversity within the workforce and technological changes (Tosi, Rizzo, \& Carroll, 1994). These are some of the aspects which could cause stress for employees within the organisation. There are all stress related illnesses such as high blood pressure, peptic ulcers, etc. that may be experienced by corporate employees within the changing organisational environment. Employees have individual factors such as personality, perception, attitudes and motivation that can have an effect on how they behave within the organisation. These factors also have an effect on their ability to cope with stressors 
in their lives. Furthermore, the environment and the individual (employee) influence each other to a great extent, and in turn, that has an effect on the productivity, personal development, relationships and satisfaction experienced by employees (Gibson et al., 2000).

\section{EMPLOYEE WELLNESS}

An increasing number of organisations have implemented employee wellness programs to, among others; address the stress that employees are experiencing within the organisation (Tosi et al., 1994). Drummond (2000) suggests that employee wellness programs are a way in which organisations can address stress directly. Stress management programs can be pro-active or re-active and these programs can improve the general health and well-being of the employees within the organisation. Occupational social workers and other workplace health and mental health professionals can become involved with formal employee wellness programs within the organisations, or they can become involved in the training department where they could focus on soft skills such as communications skills training, conflict management training, assertiveness training and stress management.

\section{METHODOLOGY}

A stress management program was presented to corporate employees to establish whether it would have an effect on their stress levels and whether play therapy mediums can be used successfully with corporate employees during a training program, to reduce their stress levels and to improve their awareness of the causes of stress in their lives and their reactions to stressors in their environment.

Qualitative and quantitative research methods were used during the research study. The two research approaches were used in conjunction with one another. The qualitative approach consisted of semi-structured interviews that were held with the participants two weeks before the stress management training. The quantitative approach included the pre and the post tests that were completed by the respondents before and after the intervention (stress management program) took place.

This study sought to determine the effect of play therapy mediums in a stress management program for corporate employees. A stress management program with the use of play therapy was developed to facilitate greater awareness amongst corporate employees regarding the effects of stress on their daily functioning, their health and job performance, and to help manage their stress levels more effectively.

\section{Research Design}

This study has a quasi-experimental design. The one-group pre-test/ 
post-test design was used to guide the study (Bailey, 1994) with probability and simple random sampling used to identify the participants for the purpose. Meetings were conducted with the Human Resources Department of ABSA Bank, one of the leading financial institutions in South Africa. The focus of the meeting was to explain the extent of the research and what resources (such as a venue) would be required. The Human Resource Department of ABSA Bank identified the Information Technology department of the organisation as a very stressful working environment, and therefore, the Information Technology department became the universe from which the sample was taken. Three project teams were working under a great amount of pressure with upcoming deadlines, and the employees of these teams were identified as possible candidates for the training. These three teams formed the population from which the sample was taken. An invitation was sent out to all the members of these teams (which consisted of about 65 people) to take part in the training. Twelve employees replied that they would like to take part in the stress management training. A group size of between ten and sixteen people is ideal for stress management training, because it is large enough for adequate group interaction to take place, but it also allows for personal attention from the social worker to each employee.

The 12 participants were from different hierarchal levels, which consisted of the project manager, 3 senior systems analysts, 4 junior systems analysts and 4 system programmers. There were five males and seven females in the group with an age range of 24 to 55 years. Ethnic make-up was African, Asian and Caucasian.

\section{Data Collection}

Semi-structured interviews were conducted with each of the participating employees, approximately a week before the stress management program was presented. The purpose of the semi-structured interviews was to ascertain what the participating employees knew about stress and the effect thereof before the training was done. Furthermore, the author was interested to find out whether there were any specific needs that should be addressed throughout the training.

During this part of the research each of the 12 employees were given a questionnaire (pre-test) to complete. The purpose was to determine what their stress levels were, before the stress management program was presented to them. The stress management program was then presented to the corporate employees over four sessions, and thereafter they completed the same questionnaire as the post-test. A comparison could then bemade regarding the pre- and post-test scores, to ascertain whether the intervention that took place had an effect on their stress levels. The stress test that was used in the sample was created by Burn and Payment (2000) and suited the needs for this study as it is a short test (12 questions) and the corporate employees did not have to spend a great amount of time on completing the questionnaire (Figure 1). 
FIGURE 1. Results of the Stress Questionnaire

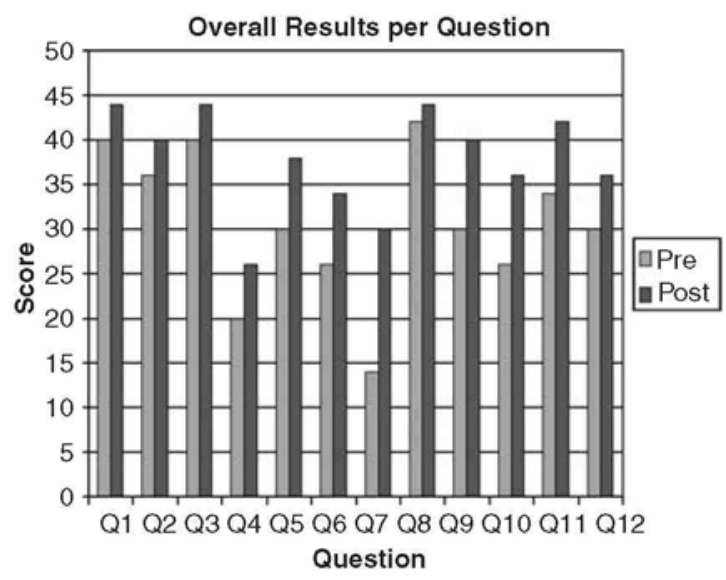

The employees were asked to rate themselves on a scale of 1 to 5 where 5 is Always, 3 is Usually and 1 is Seldom. A score of 50 to 60 indicated that the employee is taking the right measures to manage stress levels in his/her life. If the score is between 36 and 49, the employee is taking steps to manage his/her stress levels but there is more that he/she can do and he/she has to rethink their priorities. If the employee's score is 35 and lower, it is pointing towards health problems and relationship problems at home and at work. These employee's stress levels are too high and they need to make adjustments in their lifestyles (Burn \& Payment, 2000). Therefore, when looking at the graph, an increase in the scores of the post-test indicates a decrease in the stress levels of the employees, per question. The pre- and post-test results were as follows:

1. I manage my time effectively: Group pre-test, 40; Individual average, 3.33; Group post-test, 44; Individual average, 3.66.

2. I use assertive statements to protect my right to say "no" to others: Group pre-test, 36; Individual average, 3; Group post-test, 40; Individual average, 3.66.

3. I regularly show my feelings to someone close to me: Group pre-test, 40; Individual average, 3.33; Group post-test, 44; Individual average, 3.66.

4. I do volunteer work that is meaningful: Group pre-test, 20; Individual average, 1.67; Group post-test, 26; Individual average, 2.17.

5. I eat a balanced diet with lots of fresh fruit and vegetables: Group pre-test, 30; Individual average, 2.5; Group post-test, 38; Individual average, 3.67.

6. I do exercise at least three times a week: Group pre-test, 26; Individual average, 2.17; Group post-test, 34; Individual average, 2.83.

7. I practice relaxation techniques daily: Group pre-test, 14; Individual average, 1.17; Group post-test, 30; Individual average, 2.5.

8. I avoid unhealthy habits (e.g., smoking, or alcohol abuse) for coping with stress: Group pre-test, 44; Individual average, 3.5; Group 
post-test, 44; Individual average, 3.67.

9. I spend leisure time in a place where I have complete change of scenery: Group pre-test, 30; Individual average, 2.5; Group posttest, 40; Individual average, 2.5.

10. I have talked to my boss about my work commitments and expectations:

Group pre-test, 26; Individual average, 2.17; Group posttest,

36; Individual average, 3.0.

11. I have talked to members of my household to divide responsibilities:

Group pre-test, 34; Individual average, 2.83; Group posttest,

42; Individual average, 3.5.

12. I get six to eight hours sleep every night: Group pre-test, 30; Individual average, 2.5; Group post-test, 36; Individual average, 3.0.

The pre- and post-test scores of all the corporate employees but one who participated in this research study indicated diminished stress levels after completion of the stress management program. The overall results of the pre- and post-tests of the group showed a $23.37 \%$ differential in the total scores of the group.

However, one of the employees showed an increase in her stress levels after the stress management program was presented. This employee was exposed to added stress during the course of the training because her father had a heart attack and he needed to be hospitalised and cared for after the hospitalisation. She also experienced physical symptoms of stress such as nausea and migraines, and her energy levels were low throughout this period of time.

\section{The Intervention: The Stress Management Program}

The stress management program that was presented to the corporate employees was presented over four mornings and each session concentrated on a specific theme with regard to stress management. They were defining stress, physical, psychological, emotional effects of stress; stress management techniques, and a personalised stress management program.

\section{CONCLUSIONS}

\section{The Use of Play Therapy Mediums}

Play therapy mediums were used throughout the stress management training. The play therapy mediums were used to enhance the awareness of the employees with regard to their stress levels, and the effect on their daily functioning at work and in their personal lives. The employees evaluated the use of the play therapy mediums as indicated in Figure 2. All the participants were positive about the use of play therapy mediums during the stress management training. They participated voluntarily in all the activities that formed part of the program. 
FIGURE 2. Evaluation of Play Therapy Mediums

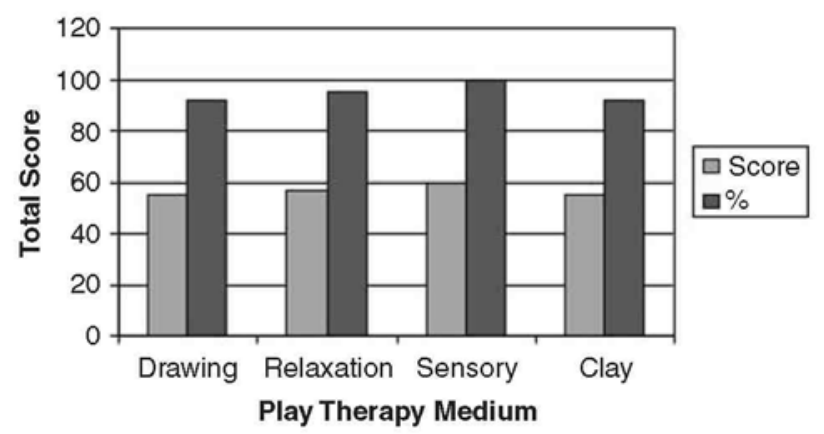

\section{Sensory Activities, Clay, Drawing and Relaxation Activities}

Figure 2 suggests that the employees enjoyed the sensory work. The sensory activities that were used included the peeling of oranges (Oaklander, 1995), music was played during all the activities and the employees were made aware of their surroundings on a sensory level on a regular basis.

\section{Clay}

The employees were requested to create their greatest stressor in the clay with their eyes closed. Thereafter, the employees had the opportunity to give feedback with regard to the activity and they could share as much as they wanted to with the group about the stressor that they created. During this session one of the women (E) felt she did not want to discuss anything in front of the group. She was given permission to discuss if she felt up to it, at a later stage. The authors asked $W$ to discuss her experience and the stressor in her life. This participant started to tell the group in a very soft voice that the stressor that she made was her daughter, and that her daughter had tried to commit suicide three times during the past year. She left the room crying-and returned five minutes later to continue with the training. (The author met $\mathrm{W}$ after the session to confirm whether she was receiving therapy. She confirmed that she and her family were receiving therapy.) After everyone in the group had had a turn, E asked whether she could have her turn again because she did not want to talk about her stressor the first time round. With the group's permission she then told the group that she divorced her husband a year ago and that she did not realise that the divorce was still having such an effect on her life.

The clay is an effective medium to bring troubling issues in the employees' lives to the foreground. They realise that they have unfinished business in their lives and that they need to address the unfinished business before they will reach a state of homeostasis-thus learn to manage their stress levels more effectively. 


\section{Drawings}

The drawings were done as a group activity and as an individual activity. The group was divided into smaller groups, and were then asked to draw the "stress." Thus they had to define stress in a drawing. This activity is effective because most times the group members draw their stressors and not "stress." This gave the researcher the opportunity to discuss the definition of stress and how stress can be positive and negative.

\section{Relaxation Activities}

Each training session started or finished with a relaxation activity. The progressive muscular relaxation activity was repeated because the author is of the opinion that relaxation is a skill that people should acquire. In the beginning it does not come naturally, but the more a person does the relaxation activity, the easier it becomes (Auerbach \& Gramling, 1998). The relaxation activity varied slightly each time it was done. Initially, the author concentrated much on the employees' breathing, the relaxation of different sets of muscles, and on their awareness of their bodies. As the training progressed, visualisation activities were included in the relaxation exercises, and the employees were invited to create their own safe place that they could return to at any time after the training was completed.

\section{Limitations of the Study}

The following limitations were taken note of as the study progressed and was completed:

- The stress management program would be even more effective if the corporate employees could be moved out of their working environment, perhaps into a more natural setting, where the atmosphere is relaxing for the corporate employees.

- If the stress management program is presented at the offices of the corporate employees, an arrangement should be made before, that they should not be called out of the training sessions for urgent work that needs to be done. This breaks the continuity of the training and the employees who go out of the sessions do not receive all the information.

- Further research should be done with regard to the enduring effects of the stress management program. The same post-test could be implemented after three to six months to ascertain whether the positive effects of the stress management program were lasting effects.

\section{SUMMARY}

The authors conducted research with a group of corporate employees. 
This research entailed a pre-test to determine stress levels of the participating employees. A stress management program was then presented to the employees, and a post-test was conducted to measured the effect of the stress management program was on reducing the stress levels of the employees.

The stress management program included play therapy mediums that were used in activities throughout the program. The results of the pre-and post-test scores indicate that the stress levels of the corporate employees who took part improved after presentation of the program. The play therapy mediums had generally a positive effect on the employees. All the employees took part in the activities, and this led to greater awareness with regard to their own stress levels, the causes of stress in their lives and the choices that they had to make to take back the control over their lives. This study supports the notion that if a stress management program includes play therapy mediums such as drawings, sand tray, clay, metaphors and fantasy, it serves to enhance self-awareness, resulting in more appropriate personal stress management.

Play therapy mediums can be used over a broad spectrum. The mediums are effective and are enjoyed by children and adults alike. Adults often do not have the time or they forget how enjoyable "play" can be. A stress management program which includes play therapy mediums, can allow adults the opportunity to play.

\section{REFERENCES}

Auerbach, S.M. \& Gramling, S.E. 1998. Stress Management: Psychological Foundations. New Jersey: Prentice-Hall, Inc.

Bailey, K.D. 1994. Methods of Social Research. 4th Ed. New York, NY: Free Press. Brehm, A.B. 1998. Stress Management: Increasing Your Resistance. Indiana: Courier Kendallville, Inc.

Burn, B.E. \& Payment, M. 2000. Assessment A to Z. San Francisco: Jossey-Bass.

Burns, R. 2003. Unwind: 10 Ways to Manage Stress and Improve Your Wellbeing. 2nd

Ed. Australia: Allen and Unwin.

Carey, L. 1990. Sandplay Therapy with a Troubled Child. The Arts in Psychotherapy, 17: 197-209.

Drummond, H. 2000. Introduction to Organisational Behaviour. New York, NY:

Oxford University Press.

Ellis, M.J. 1973. Why People Play. Prentice Hall: New Jersey.

Fincham, R.\& Rhodes, P. 1999. Principles of Organisational Behaviour. 3rd Ed. New York, NY: Oxford University Press.

Gibson, J.L., Ivancevich, J.M., \& Donnelly. 2002. Organisations Behaviour Structure Process: International Edition. 10th Ed. London: Irwin Mc Graw-Hill.

Gitlin-Weiner, K., Sandgrund, A., \& Schaefer, C. 2000. Play Diagnosis and Assessment. 2nd Ed. New York, NY: John Wiley \& Sons, Inc.

Grobler, C. \& Hiemstra, L.A. 1998. CME: South Africa's Continuing Medical Education Monthly. Stress in the Workplace, 16(1): 55.

Jennings, S. 1993. Play Therapy with Children: A Practitioners Guide. Oxford:

Blackwell Scientific Publications.

Kantor, L., Schomer, H.,\& Louw, J. 1997. Lifestyle Changes Following a Stress Management Program: An Evaluation. South African Journal of Psychology, 27(1),

March: 16-21. 
Keefe, T. 1988. Stress-Coping Skills: An Ounce of Prevention in Directs Practice. Social Casework: The Journal of Contemporary Social Skill Training, 10:

475-482.

Looker, T. \& Gregson, O. 2003. Managing Stress. UK: Hodder Plc.

McMahon, L. 1992. The Handbook of Play Therapy. New York, NY: Routledge.

Oaklander, V. 1988. Windows to Our Children: A Gestalt Therapy Approach to Children and Adolescents. Gouldsboro, ME: The Gestalt Journal Press.

Oaklander, V. 1994. Gestalt Therapy. In O'Conner, K.J.\&Schaefer, C.E. (Eds). Handbook of Play Therapy. Volume Two: Advances and Innovations. New York, NY:

John Wiley and Sons.

O'Conner, K. 1997. Using Guided Imagery to Augment the Play Therapy Process. In

Kadusen, H. \& Schaefer, C.E. (Eds). 101 Favourite Play Therapy Techniques.

London: Jason Aronson Inc.

Schaefer, C.E. (Ed). 1993. The Therapeutic Powers of Play. New Jersey, NJ: Jason

Aronson Inc.

Schoeman, J.P.\&Van Der Merwe, M. 1996. Entering the Child's World: A Play Therapy

Approach. Pretoria: Kagiso Publishers.

50 JOURNAL OF WORKPLACE BEHAVIORAL HEALTH

Strydom, H. \& Venter, L. 2002. Sampling and Sampling Methods. In De Vos, H.S. (Ed). Research at Grass Roots: For the Social Sciences and Human Service Professions. 2nd Ed. Pretoria: J.L. van Schaik Publishers.

Thompson, C.L. \& Rudolph, L.B. 1992. Counseling Children. 3rd Ed. California:

Brooks/Cole Publishing Company.

Tosi, H.L., Rizzo, J.R.,\&Carroll, S.J. 1994. Managing Organisational Behaviour. 3rd Ed. Massachusetts: Blackwell Publishers.

Van den Bergh, N. 2000. Where Have We Been? .. . Where Are We Going? Employee Assistance Practice in the 21st Century. Employee Assistance Quarterly, 16(1-2):

1-10.

Ward-Wimmer, D. 2003. Introduction: The Healing Potential of Adults Play. In

Schaefer, C.E. (Ed). Play Therapy with Adults. New Jersey, NJ: John Wiley\&Sons.

West, J. 1996. Child-Centred Play Therapy. London: Edward Arnold.

Williams, S. 1994. Managing Pressure for Peak Performance: The Positive Approach

to Stress. UK: Kogan Page.

Winship, G.\& Haigh, R. 1998. The Formation of Objects in the Group Matrix: Reflections on Creative Therapy with Clay. Group Analysis, 31: 71-81. 